\title{
Sampling and purification methods for dating by Atom Trap Trace Analysis in various environments
}

\author{
YANNIS WOLFGANG ARCK ${ }^{1}$, DAVID WACHS ${ }^{1}$, \\ MAXIMILIAN SCHMIDT ${ }^{1,2}$, LISA RINGENA ${ }^{2}$, JULIAN \\ ROBERTZ ${ }^{2}$, MARKUS K OBERTHALER ${ }^{2}$ AND WERNER \\ AESCHBACH $^{1}$ \\ ${ }^{1}$ Institute of Environmental Physics \\ ${ }^{2}$ Kirchhoff-Institute for Physics
}

Presenting Author: yannis.arck@iup.uni-heidelberg.de

Noble gas radioisotopes such as ${ }^{39} \mathrm{Ar}$ and ${ }^{85} \mathrm{Kr}$ (half-lifes of 269 and $10.8 \mathrm{yr}$, respectively) are perfectly suitable for dating environmental processes up to about 1000 years. However, the low isotopic abundance of ${ }^{39} \mathrm{Ar}$ of less than $10^{-15}$ limits the classical low level counting analysis to sample sizes of at least $1000 \mathrm{~L}$ of water. With the advent of Atom Trap Trace Analysis the required sample size for ${ }^{39} \mathrm{Ar}$ dating could be reduced drastically to less than $10 \mathrm{~L}$ of water. Also for ${ }^{85} \mathrm{Kr}$, which is not yet analysed routinely in Heidelberg, the reduction of sample size requirements is large. Sampling campaigns in remote areas or under otherwise restricting conditions in a wide range of environmental settings and with many possible objectives have hence become feasible. The time interval targeted by ${ }^{39} \mathrm{Ar}$ suits investigations on global ocean circulation, alpine glaciers and ice deposits, many groundwater systems, or even more special environments such as strongly stratified lakes or permafrost.

The usual (ground)water or ice samples are mostly not very difficult to handle concerning the sampling and subsequent purification in the lab. A dedicated vacuum setup degasses the water (or ice) and collects all gases in an activated charcoal trap. Hereafter, the mixture of gases is sent through two titanium sponge getters at different temperatures to absorb all reactive gases, leaving only the inert noble gases of which argon is by far the most abundant. An additional gas-chromatographic separation of krypton from argon is then possible if required. However, each sampling objective has its own requirements and some modifications have to be applied to the routine sampling and purification processes. An example for special circumstances is the extremely gas-rich water of Lake Kivu, necessitating sophisticated sampling methods to collect large amounts of gas without air contamination. Also the purification requires special care to get rid of the undesired bulk gases before the standardised routine noble gas extraction to avoid an overload of the getters. The melting of ice samples or permafrost is perfomed in a special vacuum container and has to be adjusted concerning sample size and released gas amount. 